\title{
STUDY OF SOIL BORN FUNGI OF RBNB COLLEGE CAMPUS SHRIRAMPUR, DIST.AHMEDNAGER, MAHARASTRA
}

\author{
${ }^{1}$ S. B. Nagpure*, ${ }^{2}$ R. G.Wakade, ${ }^{3}$ A.A.Lokhande, ${ }^{4}$ A.K.Mohite, ${ }^{5}$ A.R.Tuwar and \\ ${ }^{6}$ D.A.Tuwar. \\ 1,2,3,4 Dept. Of Botany, RBNB college, Shrirampur*(MS),india. \\ 5,6Dept. Of Botany, Arts, Commerce \& Science College, Sonai (MS), India. \\ *Corresponding Author: shubhanginagpure765@gmail.com
}

\begin{abstract}
Communicated : 15.02 .2020
Revision :20.3.2020 \&10.4.2020

Accepted : 20.05.2020

Published: 30.05 .2020

ABSTRACT:

In the present investigation, the mycoflora where investigated between August 2017 to February 2018. Soil samples were obtained by incubating petri dishes with Potato Dextrose Agar (PDA) media to room. These petri dishes were incubated at $25^{\circ} \mathrm{C}$ to $28^{\circ} \mathrm{C}$. Fungal colonies that formed within 3-5 days were isolated and identified on the basis of micro and macro morphological characteristics. Total 15 fungal species were identified from different places of soil. Aspergillus sp. , Trichoderma sp., Rhizopus sp., Mucor sp., Alternaria sp. were the most common findings. In this study environmental condition such as certain soil pH levels, humidity, temperature and moisture affect the variation among the soilmycoflora.
\end{abstract}

Key words: Soilmycoflora, Shrirampur, PDA, Humidity.

\section{INTRODUCTION:}

Fungi are usually multicellular, heterotropic, achlorophyllous and spore bearing organism. The fungi are one of the dominant group present in the soil. The heterotropic fungi obtain their organic material from external sources. The heterotrophs may exists as saprophytic and parasitic. Parasitic fungi are obtain it's nourishment from an other living organism and saprophytes gets its nourishment from dead organism and decaying organic materials. Parasitic fungi absorb nutrients from the body fluids of its host, and parasites of plants may produce specialized hyphae called haustoria that penetrate plant cell wall and lie against the plasma membrane, where they can both absorb food. Facultative parasite does not absolutely rely on any host for completion of its life cycle and obligate parasite cannot complete its life cycle without exploiting a suitable host.

Fungi grow from the hyphae that make up unique organism due to their morphological, physiological and genetic features, they are able to colonize all matrices in natural environments, in which they play key roles in maintaining equilibrium. The fungi secrete exoenzymes and endoenzymes that helps for extracellular and intracellular digestion respectively. The exoenzymes which break down solid materials into soluble compounds for absorption through their outer walls (Hussainet al., 2014). Fungi are an important component of the soil micro biota. The role of fungi in the soil is an extremely complex one and is fundamental to the soil ecosystem.

Fungi produces some useful components those are beneficial to soil health, growth and play important role in the nutritional cycle that is important part of the biological balance. (Kadam and Kore, 2017). Fungi are important as pathogens. They have role in medicine as source of many antibiotics, alone the Aspergillus produces about 20 enzymes which are industrially important. (Saler and Bhagwat, 2013). The main aim of the present study is to explored the distribution of soil borne mycoflora 
of R.B.N.B. college campus and to check the distribution of pathogenic fungi of the selected areas.

\section{MATERIALS AND METHODS:}

\section{Collection of the Soil sample:}

The soil samples were collected from R.B.N.B.College, Shrirampur campus. The exact location from which samples were collected includes,

- Botanical garden.

- Rose garden.

- Cycle stand.

- Tamarind project.

The soil samples were dried with the help of hot air oven, crushed, sieved and finally used for further studies.

\section{PDA Media preparation}

Soil fungi were cultured using PDA (Potato Dextrose Agar) medium. Composition of PDA medium, is as follows-

- Potato infusion-200gm.

- Dextrose-20gm.

- Agar-20gm.

- $\quad$ Distilled water-1000ml.

Media was sterilized in autoclave at $121^{\circ} \mathrm{C}$ and $15 \mathrm{LBs} /$ psi pressure for 15 minutes.

\section{Isolation of fungi from soil by serial dilution method}

The collected soil samples were mixed with sterile distilled water to make a soil suspension. Soil suspension was prepared by adding $1.0 \mathrm{~g}$ soil sample to $10 \mathrm{ml}$ distilled water. $1 \mathrm{ml}$ of prepared soil suspension was added to $9.0 \mathrm{ml}$ of water to made 1:10 dilution and were mixed vigorously for uniform distribution. $1 \mathrm{ml}$ of suspension from 1:10 dilution transferred to next test tube gave 1:100 dilution, then 1:1000 dilution and lastly 1:10000 dilution were made.

\section{Inoculation:}

From 1:10000 dilution $1 \mathrm{ml}$ was pipetted on to petri plates containing cooled PDA Media. Petri plates were covered with cover glasses and incubated at $27^{\circ} \mathrm{C}$.

\section{Identification:}

After 2-7 days, fungal colonies were appeared on the PDA media. Compound microscope (makeBesto, model- 10B, 13019/09, magnification$10 \mathrm{x}$ and $45 \mathrm{x}$ ) was used to determine the morphological structure of fungi after mounting in cotton blue covered with cover slip on slides. Photographs of slides are mounts were taken with the help of Mobile phone camera (Galaxy on5 pro). Identification of fungal species was based on microscopic observation and using mycological literature. (Hussainet al. 2014; Kadam and Kore 2017).

\section{RESULTS AND DISCUSSIONS:}

In present study soil samples from different sites i.e. Botanical garden, Tamarind project, Cycle stand and Rose garden of college campus was collected. The study was conducted during the month of August 2017 to February 2018. Results obtained were shown in Table-1, it was observed that total 15 species belonging to 11 genera were isolated from sampling sites with 2 fungal type which are not identified are grouped under Unidentified $1^{\text {st }}$ and Unidentified $2^{\text {nd }}$. From this study it was observed that Botanical Garden is richest in fungal diversity as compared to others. It showed presence of 13 fungal species belonging to 9 genera with one unidentified fungal species. Next were Rose garden with 11 fungal species belonging to 6 genera with one unidentified fungal species. Least diversity was recorded at Cycle stand 6 fungal species with 5 genera with one unidentified fungal species. Because soil found in this area is dry and have unfavourable conditions for fungal growth.

$$
\text { Among them Aspergillus niger, }
$$

Trichoderma sp., Rhizopus sp.and Mucor sp. are most dominant found in all sampling sites. In parking area of Cycle stand, least number of 
fungal species found to be present depending upon number of environmental conditions.

In present study pathogenic fungal species like Rhizoctonia solani, Fusariu moxysporum, AspergillusflavusandAlternaria sp. were recorded.

\section{CONCLUSIONS:}

From above discussion we concluded that Botanical garden have richest diversity of soil fungi followed by Tamarind project and Rose garden. Botanical garden is richest diversity of soil mycoflora because they have favourable environmental conditions like soil $\mathrm{pH}$, humidity, temperature and moisture.

Pathogenic fungal species like Rhizoctonia solani, Alternaria alternata, Aspergillus flavus and Verticillum sp. also recorded from our study, they are capable of causing serious diseases of many crop plants.
Penicillium sp. and Rhizopus sp. have important role in food industry, fermentation process and biotechnologically important enzymes.

\section{REFERENCES:}

Kadam A.S. and Kore B.A. (2017).Diversity of soil mycoflora of Gerbera cultivation in Polyhouse from Satara district, Maharashtra. Flora and Fauna.vol.23(1):5052.

Saler R.S. and Bhagwat.M.G. (2013).Diversity of soil micro fungi from Kalwantaluka region-2 of Nashik District, Maharashtra. Flora and Fauna.vol.19(1):90-92).

Tanveer Hussain, M. Ishtiaq, Shehzad Azam, WaheedaJ awad and Irfanul Haq (2014).Comparative analysis of air, soil and water mycoflora of Samahni Area, District Bhimber, Pakistan. African Journal of Microbiology Research.vol.8(23):2295-2306.

Table-1 Occurrence of Soil Borne Fungal Species in various Places of R.B.N.B. College.

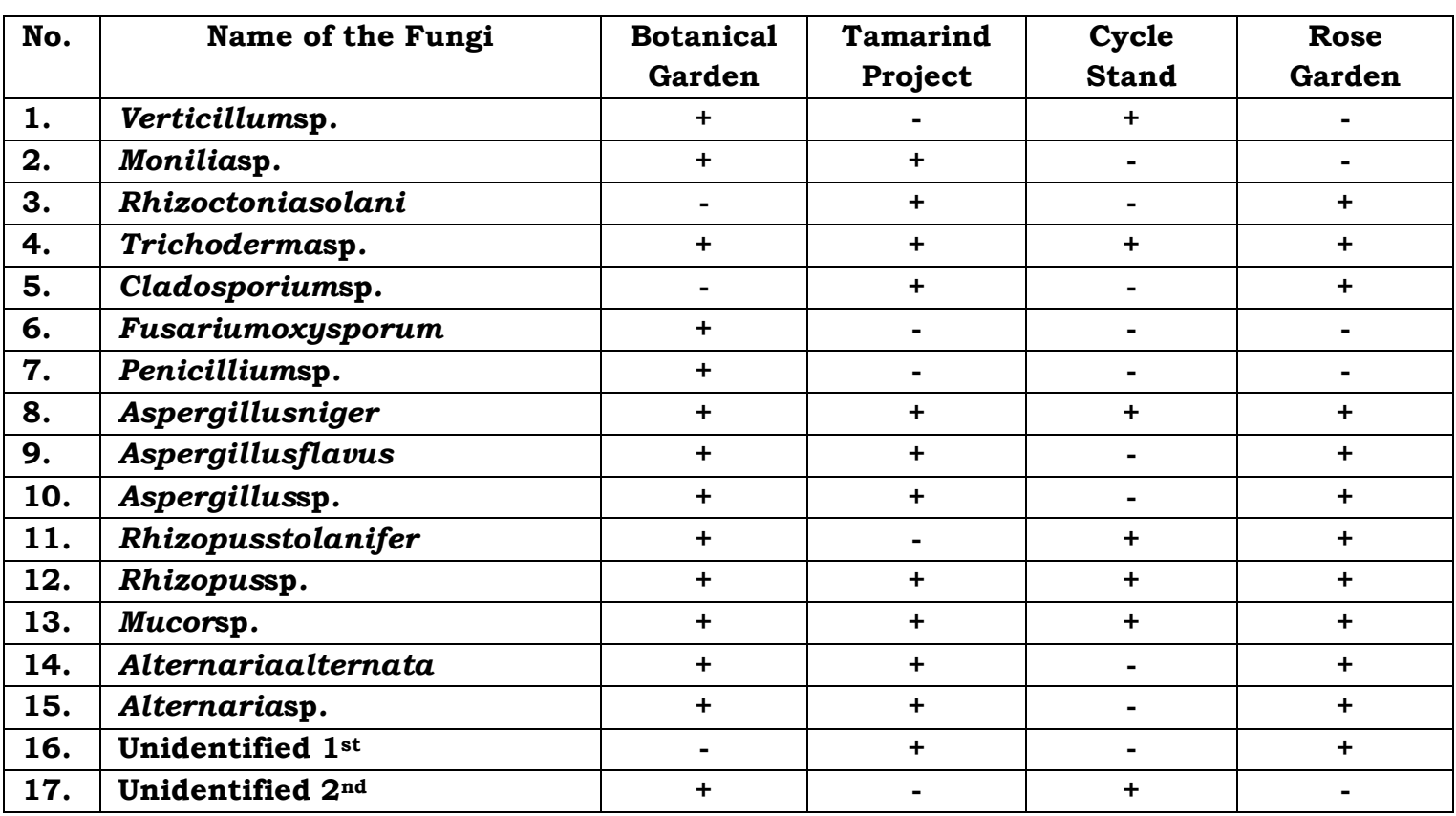

Abbreviations- + = Present of fungal species - =absent of fungal species 
I J R B A T, Issue (VIII), Vol. II, May 2020: 32-38

A Double Blind Peer Reviewed Journal
OPEN $\odot$ ACCES

e-ISSN 2347 - 517X

Original Article

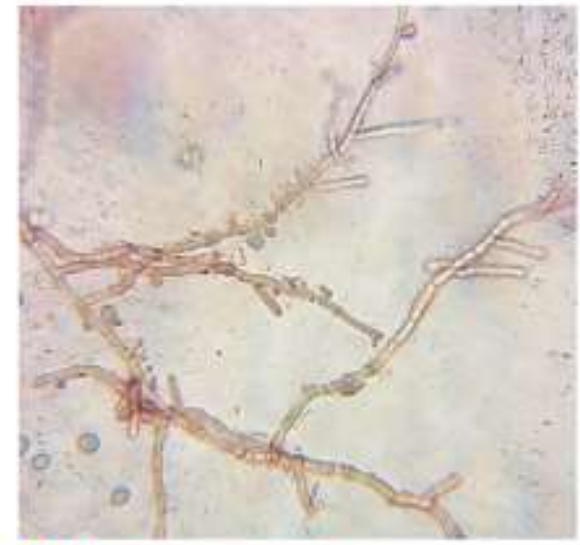

(1) Verticillum sp.

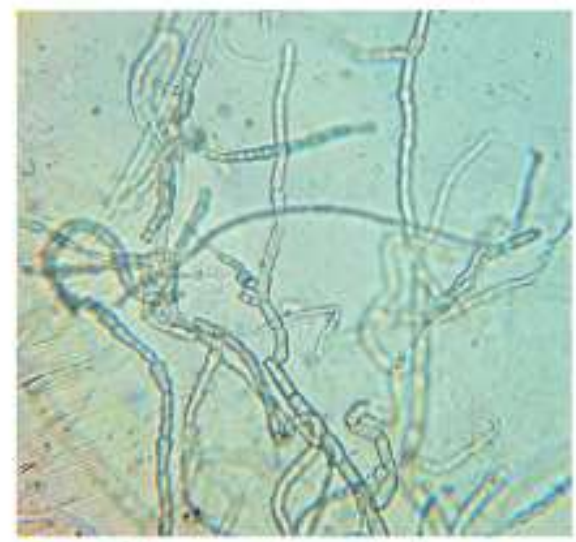

(3) Rhizoctonia solani

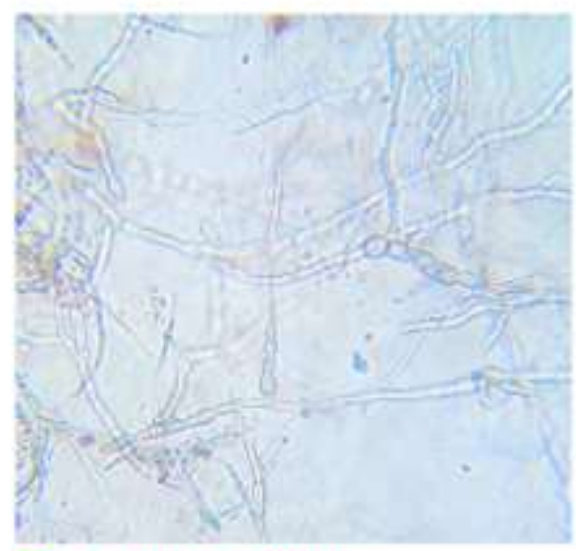

5 Cladosporium sp.

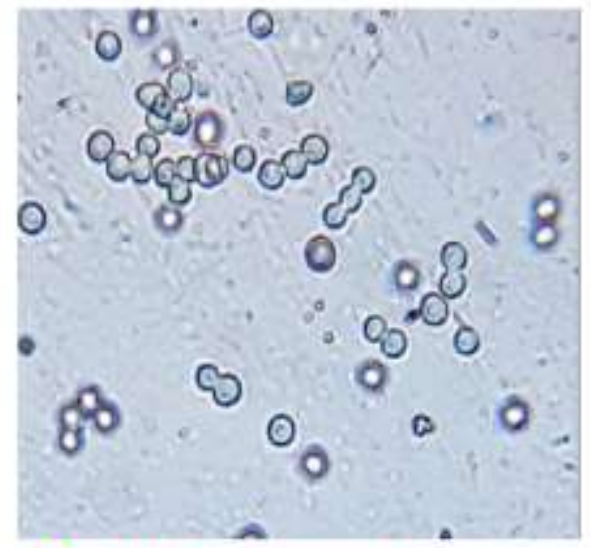

2 Monilia sp.(conidia)

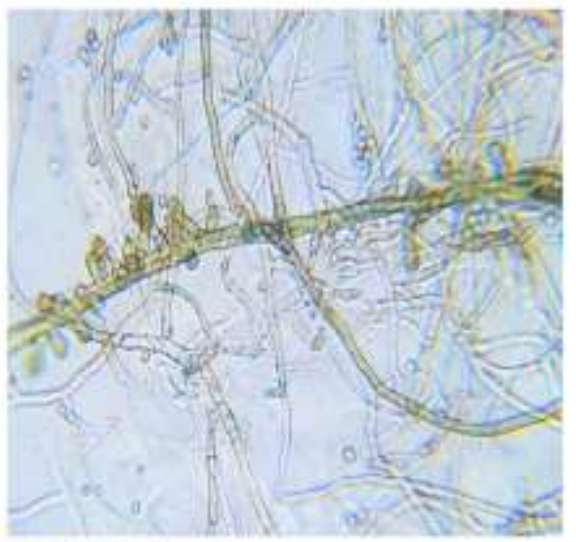

(4) Trichoderma sp.

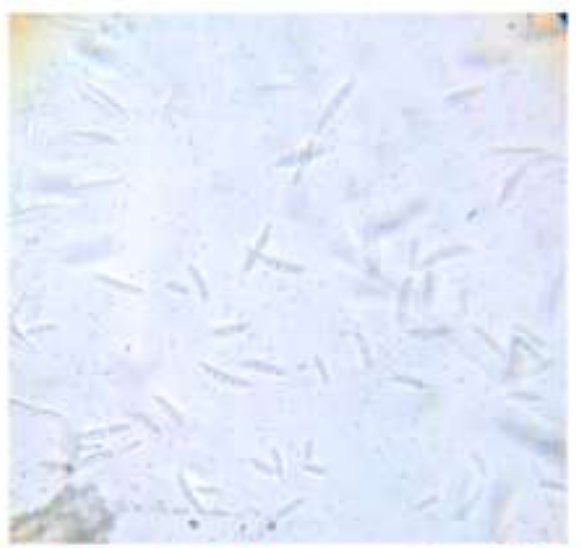

6 Fusarium oxysporum(conidia) 
I J R B A T, Issue (VIII), Vol. II, May 2020: 32-38

A Double Blind Peer Reviewed Journal

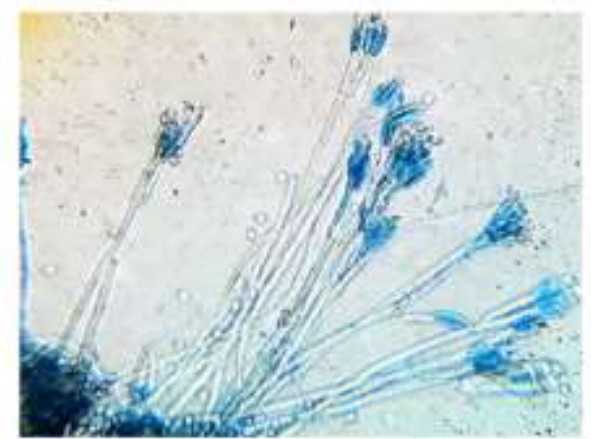

(7) Penicillium sp.

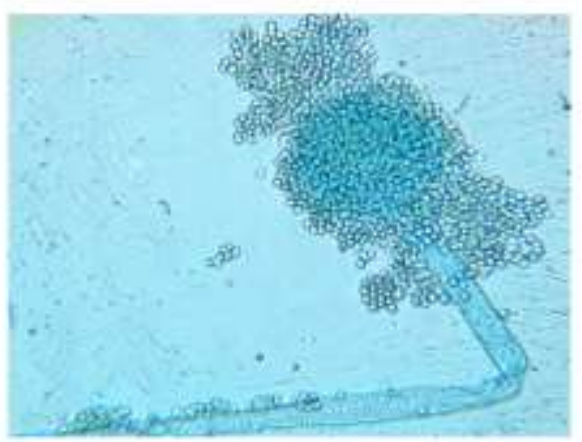

9 Aspergillus flavus

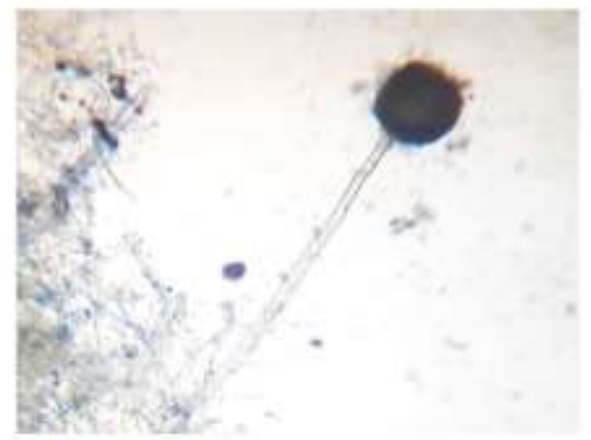

(11) Rhizopus stolanifer
OPEN@ACCES

e-ISSN 2347 - 517X

Original Article

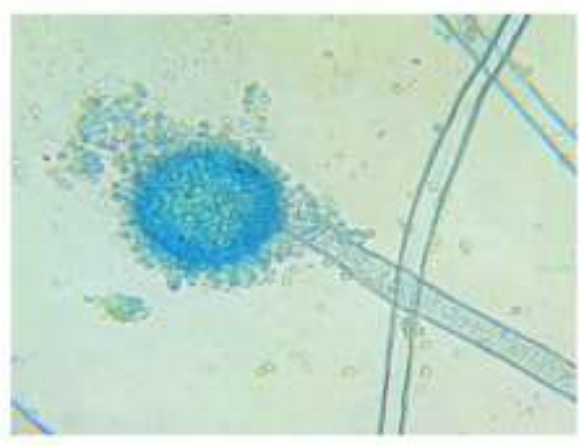

8 Aspergillus niger

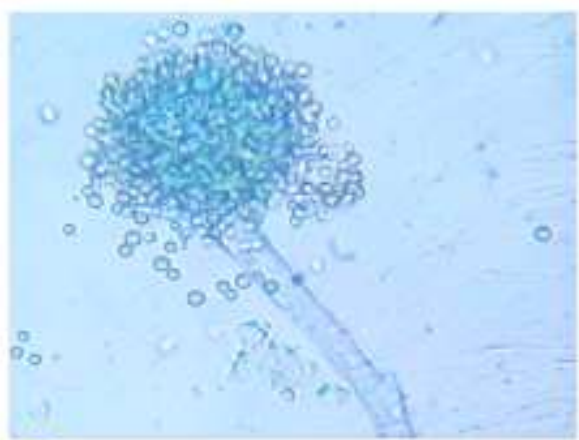

10 Aspergillus sp.

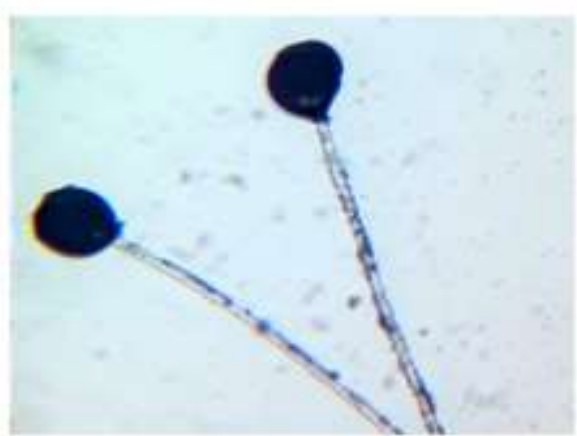

(12) Rhizopus sp. 
I J R B A T, Issue (VIII), Vol. II, May 2020: 32-38

A Double Blind Peer Reviewed Journal
OPEN $\bullet$ ACCES

e-ISSN 2347 - 517X

Original Article

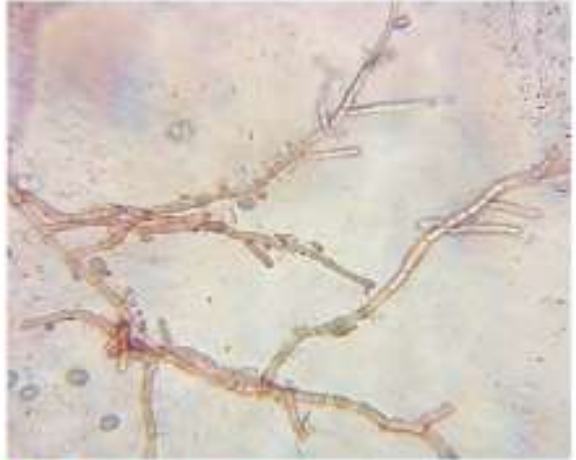

(1) Verticillum $\mathrm{sp}$.

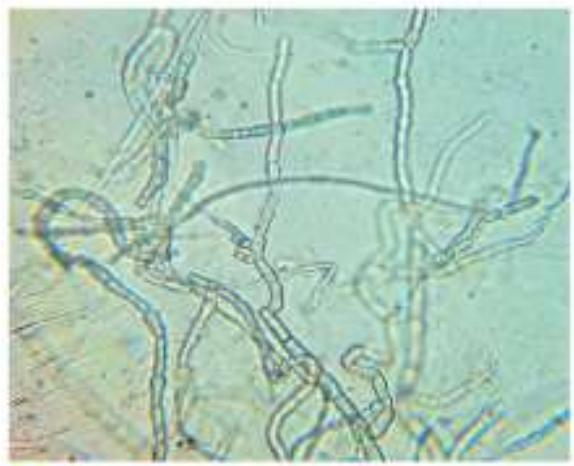

3 Rhizoctonia solani

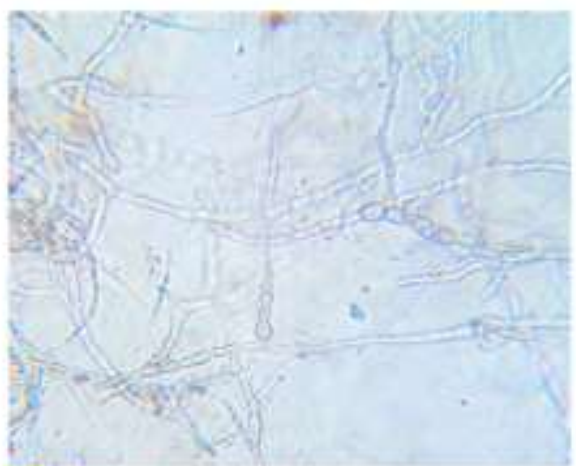

5 Cladosporium sp.

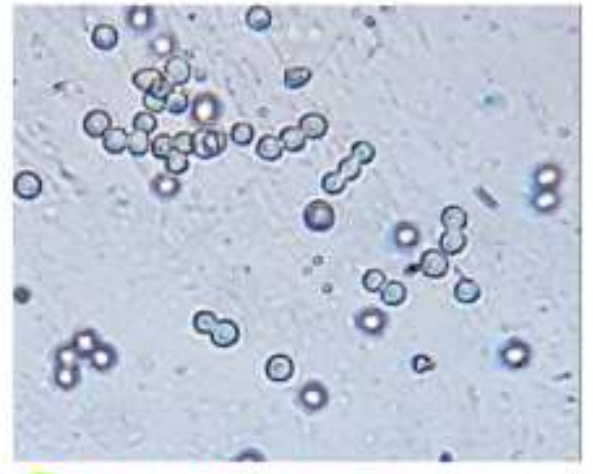

2 Monilia sp.(conidia)

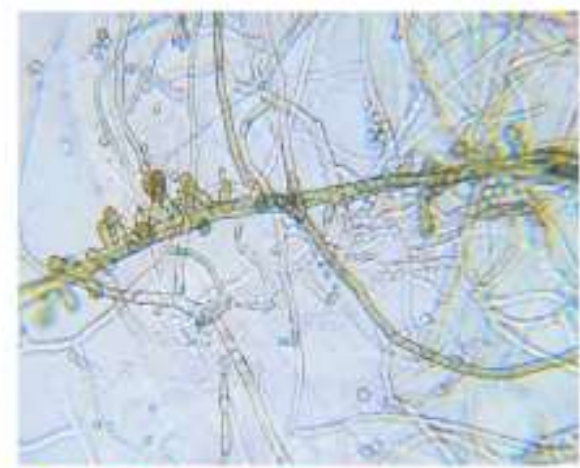

(4) Trichoderma sp.

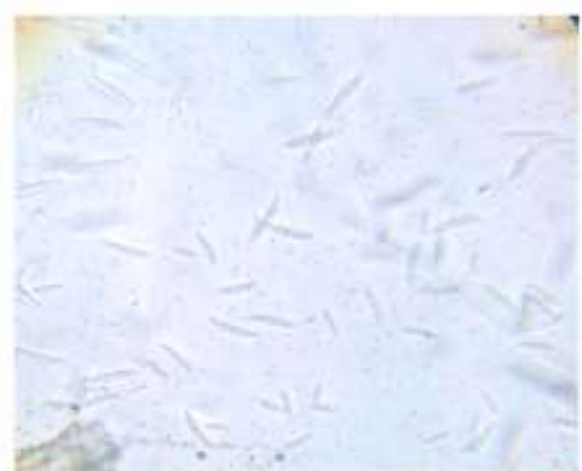

6 Fusarium oxysporum(conidia) 
I J R B A T, Issue (VIII), Vol. II, May 2020: 32-38

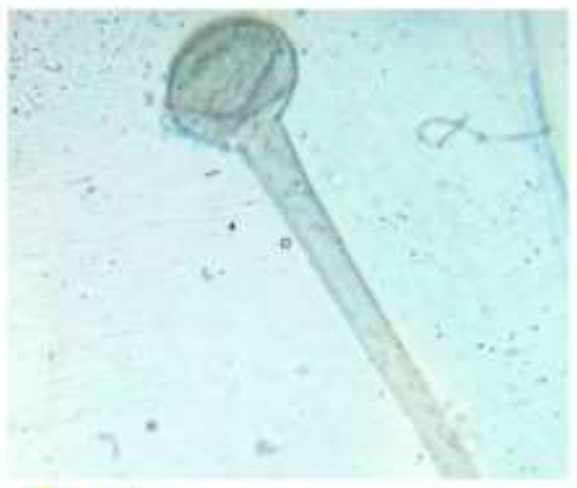

13 Mucorsp.

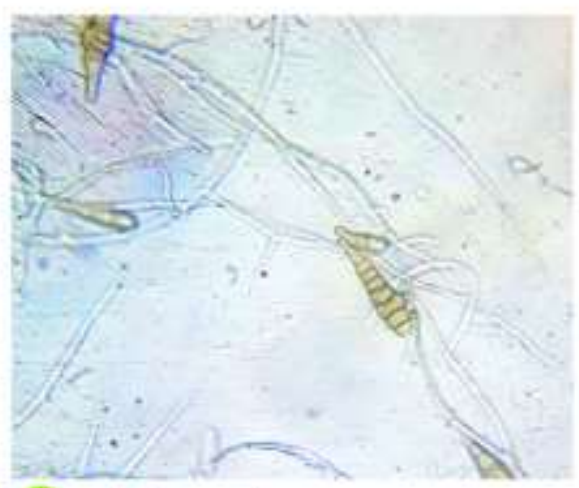

15 Alternaria sp.

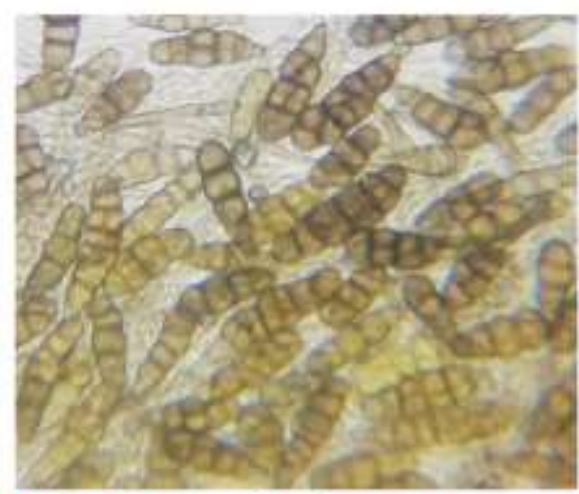

14 Alternaria alternata

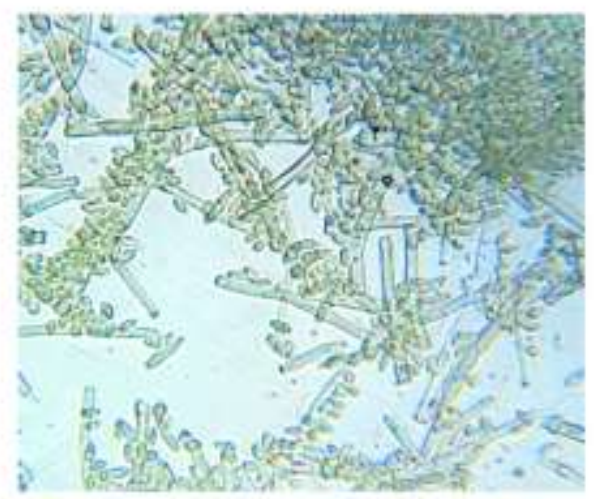

(16) Unidentified $1^{\text {st }}$

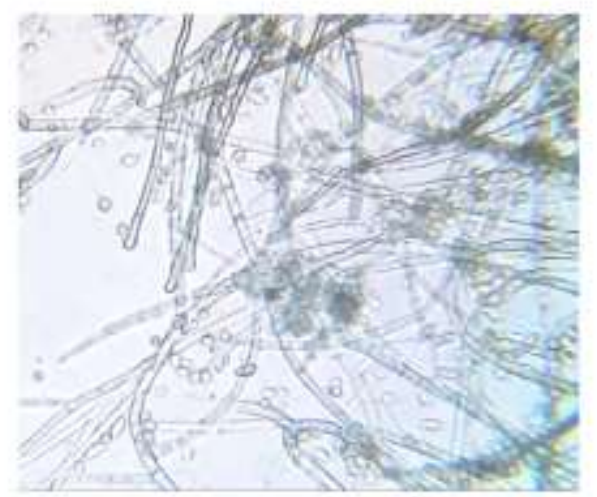

17 Unidentified $2^{\text {nd }}$ 